\title{
HUME E A EPISTEMOLOGIA: UMA LEITURA DOS NOVOS ESTUDOS HUMEANOS
}

\author{
Anice Lima de Araújo* \\ anice1981@gmail.com
}

Desde a publicação da primeira edição portuguesa de Hume e a Epistemologia ${ }^{1}$, em 1984, João Paulo Monteiro propõe uma leitura distinta da tradicional interpretação feita à filosofia de David Hume. Como ele nos diz no Prefácio à edição brasileira de Hume e a Epistemologia (2009), o capítulo inicial nos mostrará "a filosofia de Hume revertida de um caráter teórico: a ciência da natureza humana", longe da interpretação observacionalista e, como muitos acreditam, empirista. Os vinte e cinco anos que se seguiram à edição portuguesa apontaram para dois outros importantes aspectos da filosofia de Hume. O primeiro aspecto, já tratado na edição portuguesa, é o conceito de causa inobservável, o segundo é o conceito de indução, que a partir de agora será "reduzido ao plano do raciocínio causal".

Em 2003, João Paulo Monteiro publica Novos estudos humeanos ${ }^{2}$, e nos mostra, no quinto capítulo deste livro, os "equívocos gerados por Bertrand Russell ao atribuir a Hume uma teoria cética acerca da indução, gerando um dos mais influentes mitos da filosofia do século XX"

* Universidade Federal de Minas Gerais.

1 MONTEIRO, J. P. Hume e a Epistemologia. 1ㄹ Ed. Brasileira da obra publicada em 1984 pela Imprensa Nacional, Lisboa. São Paulo: UNESP, 2009.

2 MONTEIRO, J. P. Novos Estudos Humeanos. 1a Ed. São Paulo: UNESP, 2003.

3 MONTEIRO, J. P. (2003), p. 11.

KRITERION, Belo Horizonte, no 124, Dez./2011, p. 529-539. 
Em os Problemas da Filosofia (1912), Russell apresenta uma concepção da indução clara e fortemente inspirada na epistemologia de David Hume. A questão, muito bem vista por Monteiro, é a de que Hume nunca utilizou o termo indução em sua obra, ainda porque sua filosofia tem o objetivo de oferecer uma explicação acerca de inferências causais, ou seja, relações de causas e efeitos e não de objetos e qualidades como no exemplo "todos os corvos são pretos". Essa relação entre a corvidade e o pretume não é tomada por Hume em sua filosofia. Ou seja, para Hume "não temos o problema da indução, mas sim o problema da causação"4.

Além dos dois aspectos já observados por João Paulo Monteiro, acerca do observável e a teoria sobre a indução, seu livro, Hume e a Epistemologia, tem outro grande traço de inovação, a saber: sua visão acerca do naturalismo humeano. Apesar de ser um tema tão debatido entre estudiosos de Hume, em Hume e a Epistemologia temos uma definição clara do modo como o naturalismo de Hume ocorreu a partir de uma leitura dos Diálogos acerca da religião natural.

De acordo com João Paulo Monteiro, "há dois níveis na teoricidade dos princípios não puramente empíricos da natureza humana: (i) princípios explicativos, concebidos como mecanismos completamente inacessíveis à observação ou à introspecção; e (ii) disposições que, uma vez descobertas, podem ser encontradas por meios empíricos, mas que apenas parcialmente são manifestas e, por isso, também precisam do trabalho de construção teórica que gere os primeiros, e em oposição a estas disposições completamente manifestas, como os princípios de associação de ideias que são "princípios empíricos e não teóricos"5.

Muitos filósofos anteriores a Hume tentaram mostrar que inferências causais eram baseadas na razão, teoria a que Hume se opôs fortemente na seção IV da Investigação sobre o entendimento humano 6 . Hume, ao contrário, colocou como princípio dessas inferências causais uma "disposição inata, capaz de se deixar afetar por conjunções repetidas", disposição esta que chamou de hábito ou costume na seção V da Investigação.

A perspicácia de João Paulo Monteiro foi mostrar que o hábito, enquanto um princípio inato, é teórico e não se apresenta permanentemente à mente humana, deixa-se perceber apenas em algumas ocasiões, não sendo, portanto, completamente oculto, como ocorre no processo de formação de crenças. 
Uma grande diferença que encontramos entre as duas edições, a portuguesa de 1984 e a brasileira (2009) está no conceito de indução ou, como agora devemos falar: inferência causal. Esta mudança deve-se, primeiramente, ao fato de Hume nunca tratar, como nos mostra João Paulo Monteiro, o conceito de indução como inferência causal, uma vez que: "Hume nunca se ocupou do problema do raciocínio indutivo em geral, apenas com a questão do raciocínio causal" ". De acordo com Monteiro, a descoberta de qualidades não causais nos objetos nos fornece apenas uma constatação empírica que em nada nos leva a uma inferência.

Vejamos como estes temas se desenvolvem ao longo do texto.

No primeiro capítulo de Hume e a epistemologia, denominado "A teoria e o inobservável”, João Paulo Monteiro analisa a tradicional interpretação observacionalista da filosofia de Hume. Este termo, observacionalismo, foi cunhado por Randall em 1966 e aceito por muitos intérpretes, tais como Ayer (1972), Passmore (1968), Basson (1958) e Popper (1973) - o último aplicou o termo não só a Hume como também a Locke e Berkeley, entre outros.

Embora Hume, como já dissemos, nunca tenha citado o termo indução, a teoria humeana da causalidade é também conhecida como teoria da indução e, deste modo, "toda inferência baseada no que chamamos generalização indutiva é, para ele, uma inferência causal, pois todo conhecimento da natureza assenta-se na descoberta de algum tipo de relação causal"».

A mais conhecida teoria humeana é certamente a da inferência causal, pois: "dada a repetição passada, e por ação de um princípio de nossa natureza, o costume ou o hábito, a relação causal é descoberta pelo espírito antes que nossos sentidos experimentem um nova conjunção dos mesmos objetos"9. E, deste modo, a inferência causal, ao contrário do que esperam os observacionalistas, permitir-nos-ia transpor os limites do observável.

A partir das definições do termo causa, fornecidas por Hume, percebemos que sempre temos a concepção de causa como um objeto repetidamente anterior e contíguo a outro, o seu efeito. E, nos moldes da teoria humeana da inferência, concordamos que: "a causa para ser conhecida deverá ser um objeto ou evento observável, e a inferência a qual se descobre a causa de um objeto ou evento só é possível depois de observada a conjunção dessa espécie de objeto com outra, que constantemente a antecede em nossa experiência"10. 
Assim, podemos concluir que "a inferência causal transcende a observação, mas apenas na medida em que vai além de causas já observadas, não além de eventos observáveis" "11.

Para João Paulo Monteiro, a filosofia de Hume enquanto uma ciência da natureza humana deverá caracterizar-se como descoberta de novas causas e princípios; o que para o autor escocês fundamentou-se na busca por princípios da natureza humana, tais como as "associações de ideias" e o "hábito". Neste momento, a sutileza do texto de João Paulo Monteiro está no fato de que o hábito não é observável, sendo possível observamos apenas a repetição. Concluindo, portanto, que: "as inferências causais são causadas pela repetição, e esse fenômeno é, por sua vez, causado por um princípio na natureza humana chamado de costume ou hábito"12.

Para Hume, o mundo da ciência e todos os problemas do conhecimento gerados neste mundo tratam dos observáveis que geralmente chamamos de causas e efeitos. Todavia, as regularidades observáveis são produzidas por mecanismos inobserváveis, e são estes que interessam à ciência. ${ }^{13}$

No segundo capítulo, "A hipótese da gravidade", após citar várias partes da obra de Hume que apresentam uma sincera fidelidade à filosofia natural de Newton, João Paulo Monteiro inicia sua análise sobre a principal influência newtoniana na filosofia de Hume. Trata-se do conceito de gravidade a que Hume se refere em três momentos: dois deles na Investigação (VII, I) e (IV, I) e uma vez no Tratado da natureza humana (I, III, 8). Diante desses três momentos, Monteiro observa uma aparente contradição, uma vez que, no primeiro (VII, I), o conceito de gravidade aparece como efeito, no segundo (IV, I), como causa e, no terceiro (I, III, 8), como uma conjunção de causas e efeitos.

Ao refletir sobre o segundo (IV, I), João Paulo Monteiro nos mostra que uma causa é necessariamente um objeto, um evento observável, assim como nossos exemplos de relações causais são sempre observáveis. O problema começa quando tentamos admitir que a gravidade é uma causa, uma vez que a única coisa que observamos é que "corpos caem em direção à terra, que outros giram em suas órbitas etc." 14 . E, assim, se tomada como causa, a gravidade não é, de modo algum, observável, e só poderíamos aceitar a gravidade como uma causa "caso fosse uma causa inobservável"15. 
Mas João Paulo Monteiro nos mostra que, assim como o hábito é uma causa inobservável de nossas inferências causais, podemos aceitar, também, o conceito de gravidade definido como uma causa inobservável. $\mathrm{O}$ desejo de Hume de ser o Newton das ciências humanas novamente configura-se aqui, uma vez que: "a descoberta de princípios causais pela ciência aparece caracterizada como descoberta de poderes e forças secretas, isto é, de princípios em si mesmos inobserváveis, e não de causas diretamente perceptíveis"16.

Ao analisar o primeiro texto de Hume acerca da gravidade - Investigação (VII, I) - João Paulo Monteiro nos diz que:

É de plena conformidade com Newton que Hume considera a gravidade um princípio geral: uma força que, apesar de inobservável, pode legitimamente ser postulada como causa de certos fenômenos, em razão do poder explicativo que possui no interior da teoria newtoniana. ${ }^{17}$

Para João Paulo Monteiro, a aparente discrepância ao tratar do conceito de gravidade não impede que a consideremos como um princípio inobservável explicativo de eventos empíricos observáveis. Hume simplesmente escreveu estes trechos, sem pensar, é claro, em teorias observacionalistas e em como estas o leriam. Isto pode ser claramente observado no terceiro texto de Hume - Tratado (I, III, 8) -, pois ele pretende, no Tratado, fornecer um exemplo de conjunções entre causas e efeitos.

O terceiro capítulo, "Kant leitor de Hume", analisa a ligação amplamente comentada e apreciada, mais por parte de Kantianos do que em meios humeanos. Neste capítulo, João Paulo Monteiro responderá a algumas questões, entre elas: "será o conceito de causa efetivamente deduzido da experiência, na filosofia humeana, no sentido emprestado a essa expressão pela interpretação kantiana? Será esse conceito, por outro lado, efetivamente um resultado da pura e simples imaginação? Terá a associação e o hábito, em Hume, o papel que lhes é atribuído na introdução da Crítica da razão pura?" 18.

Em primeiro lugar, a Crítica da razão pura atribui a Hume a tarefa de derivar o conceito de causa do hábito. Contudo, para Hume, o hábito não é decorrente da experiência, mas, sim, um princípio da natureza humana, "claramente anterior a qualquer experiência". ${ }^{19}$ A leitura kantiana da filosofia de Hume é, no mínimo, equivocada, pois Hume não confere à experiência o 
conceito de causa e, em segundo lugar, porque, além de não estar fundada na imaginação, no sentido kantiano, está fundada em uma das faculdades da imaginação que no Tratado Hume chama de entendimento.

É interessante notarmos que toda a interpretação que Monteiro chama de equivocada, por parte de Kant, deve-se à recusa do naturalismo humeano, uma vez que, para o filósofo da Crítica da razão pura, o naturalismo "não seria legitimável, por suas teses irem além do que a experiência permite, ou seja, nesse ponto, Kant aparenta ser mais "empirista" do que o próprio Hume" ${ }^{20}$. O conceito de causa surge, indiretamente, como tendo origem na própria natureza, e Kant deveria ter mencionado, caso quisesse manter o tom irônico, que o conceito de causa, em Hume, é bastardo da natureza, e não da imaginação.

O quarto capítulo, intitulado "Indução e seleção natural", no livro de 1984, recebe o nome de "Causalidade e seleção natural" em concordância com o novo e correto vocabulário que devemos agora utilizar ao falar sobre Hume. Neste capítulo, Monteiro duvida da interpretação tradicional de Hume que acreditaria que sua teoria acerca da causalidade se restrinja meramente a "uma descrição psicológica dos efeitos do hábito"21, e procura investigar se não encontraremos "uma explicação da presença do hábito entre os princípios da natureza humana"22. O passo inicial para essa investigação estaria no final da parte I da seção V da Investigação, quando Hume sugere que poderia terminar naquele momento seu argumento, mas que sua curiosidade o leva a pesquisas maiores.

De acordo com João Paulo Monteiro, essas pesquisas embebidas na curiosidade nos trazem um belo argumento, a saber: "o hábito é um instinto implantado em nós pela sabedoria da natureza e, como instrumento de sobrevivência, o hábito é incompativelmente superior às falaciosas deduções de nossa razão"23. Como bem observa em uma das mais belas passagens de Hume, "uma das consequências do hábito é uma espécie de harmonia préestabelecida entre o curioso da natureza e a nossa sucessão de ideias", ${ }^{24}$ e não há aqui uma adoção, por parte de Hume, da metafísica leibniziana. Assim como "uma explicação teleológica do hábito e do sucesso de suas operações 
como causas finais não poderia nunca merecer mais do que o desprezo e a ironia de Hume"25.

Utilizando-se de um argumento de Antony Flew, João Paulo Monteiro reafirma que o argumento de desígnio nos proíbe qualquer interpretação de "uma sabedoria da natureza em termos teístas ou teleológicos" ${ }^{26}$. Mas, qual seria uma explicação aceitável para os parágrafos finais da parte II da seção V? João Paulo Monteiro utiliza-se, de forma sábia e inesperada, da hipótese religiosa de Cleanto nos Diálogos sobre a religião natural ${ }^{27}$ para buscar uma explicação para teoria de Hume. Essa hipótese, baseada no argumento de desígnio, nos diz que "a natureza é regulada por princípios e máximas muito semelhantes aos nossos: a curiosa adaptação dos meios aos fins, em toda a natureza, assemelha-se exatamente, embora as exceda em muito, às produções do engenho humano: do desígnio, pensamento, sabedoria e inteligência dos homens" 28 .

Fílon critica este argumento e propõe como alternativa "um princípio imanente como explicação da ordem, ajustamento e adaptação que contemplamos na natureza"29. Para Fílon, "nenhum ser vivo não adaptado a seu meio ambiente é capaz de sobreviver, de modo que não tem sentido algum insistir em sua admirável adaptação" 30 .

Deus é uma hipótese que vai contra qualquer filósofo newtoniano, nos diz João Paulo Monteiro e a "eliminação dos inaptos é claramente um princípio de seleção natural”. Apesar de propor uma explicação através da seleção natural, Hume, na voz de Fílon, não possui uma linguagem evolucionista ${ }^{31}$; o que temos nos Diálogos é um "conceito pré-darwiniano" de seleção natural, e não um "conceito pré-darwiniano de evolução".

A análise feita por Monteiro observa que a argumentação de Fílon nos Diálogos é a única capaz de dar significado à solução cética para o problema do raciocínio causal. Podemos dizer que, a partir da análise dos Diálogos, temos uma teoria naturalista de Hume inovadoramente percebida por João Paulo Monteiro, onde este nos diz que: 
A explicação humeana dessa nossa capacidade - raciocínio causal - depende de uma estrita relação entre sua concepção da natureza humana e sua visão do mundo, (...) concebendo o homem como um produto da seleção natural - e parte da natureza ${ }^{32}$.

A análise feita por João Paulo Monteiro a conclusão dos Diálogos acerca da religião natural se concentrará na aparente reviravolta de Fílon, em que este parece aceitar o essencial das conclusões do finalismo de Cleanto e de sua concepção acerca da Divindade, da natureza e das relações entre ambas.

De acordo com João Paulo Monteiro, todos os argumentos expostos por Fílon, da primeira à penúltima parte dos Diálogos, nos levam a crer em teses naturalistas opostas ao teísmo. Explicar esta mudança através de uma ironia, como o fez Price (1965) e Noxon (1973) é pouco para nosso autor, há mais do que ironia naquela passagem.

Toda a análise aqui proposta será feita sobre o princípio da simplicidade ou parcimônia evocado por Fílon na $12^{\mathrm{a}}$ parte dos Diálogos. Para Hume, observa João Paulo Monteiro, "a simplicidade serve como um poderoso critério de

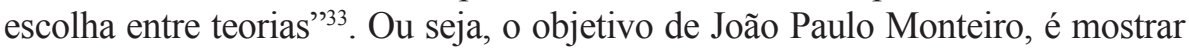
que Fílon é sutil ao pretender justamente o contrário de seu aparente fascínio por uma suprema inteligência como autora da ordem e da adaptação da natureza. Caso Fílon não se utilizasse de ironia ao tratar da anatomia proposta por Galeno, sugestão esta que nos diz que percebemos mais ou menos seiscentos músculos diferentes e que descobriremos que em cada um deles a natureza deve ter ajustado pelo menos dez circunstâncias diferentes de modo a atingir o fim a que se propôs, ele apresentaria uma completa contradição aos argumentos dele mesmo, Fílon e, consequentemente à filosofia de Hume. A resposta para este desafio está, segundo Monteiro, na oitava parte dos Diálogos, onde Fílon nos diz que: "a aparência de arte e ofício que observamos atualmente na natureza é um princípio inerente de ordem e adaptação, oposto ao princípio exterior que era o desígnio divino"34. O que Fílon quer dizer, explica João Paulo Monteiro, é que a "seleção de cada fenômeno anatômico pela natureza não manifesta, segundo a hipótese mais simples, a presença de uma nova causa, pois o que revela é sempre a operação da mesma causa ou princípio geral, o princípio da seleção de Fílon"35.

A originalidade interpretativa do autor luso-brasileiro é perceber que, por trás do aparente elogio à teoria de Galeno, Fúlon mostra que "o filósofo religioso 
inventa uma nova causa, um novo desígnio do criador"36. E, assim, deixamos de pensar que Hume, na voz de Fílon, cometeu o maior exemplo de contradição de sua obra e acreditamos que essa é uma grande "chacota" filosófica.

Hume foi sabidamente acusado de ateísmo. Publicar escritos que tratassem do tema da religião, mesmo que fossem contra a falsa religião, como a superstição e o entusiasmo, poderiam causar desconforto com a ortodoxia vigente. Só havia para Hume duas soluções: "ou silenciar totalmente quanto a tão delicados assuntos ou envolver seu discurso em artifícios e estratagemas que lhe garantisse ao mesmo tempo certa fidelidade a si próprio e a impunidade perante uma ameaça de repressão sempre presente" 37 . João Paulo Monteiro nos chama a atenção para o modo como os escritos sobre religião de Hume foram e são tratados por seus intérpretes. Muitos não atribuem real valor a estes textos e muitas vezes chegam a ignorá-los. Devemos, para entender corretamente os escritos humeanos sobre a religião, pensar corretamente na presença de um discurso estratégico causado principalmente pelo receio à censura.

Os Diálogos, dado o tema, Hume só autorizou serem publicados após sua morte, o que aconteceu em 1776. E, nem por isso, nos lembra João Paulo Monteiro, Hume foi melhor tratado por se abster em público de tais assuntos. Ao contrário, sempre foi acusado de ceticismo e nunca conseguiu uma cátedra na faculdade de filosofia.

No capítulo "Prazer e realidade: Hume e Freud", sétimo capítulo de Hume e a Epistemologia, tem-se o objetivo de verificar "em que termos foi possível pensar, no século XVIII, a oposição entre prazer e realidade, discussão essa que se tornará central nos séculos XIX e XX"38.

João Paulo Monteiro inicia seu texto descrevendo o lugar do princípio do prazer na teoria psicanalítica, a saber: "o de um fundamento absoluto de uma instância reguladora dos processos anímicos inconscientes que constituem o ponto de partida da teoria"39. Este princípio pode ser representado como uma tendência a se buscar o prazer e evitar o desprazer.

Em contrapartida, é este o princípio que constitui o início da teoria das paixões de Hume, a saber: buscar o prazer e evitar a dor. Assim como em Freud, para Hume "o solo originário de toda ação humana é constituído por processos anteriores a qualquer manifestação da consciência, inteiramente governados pela tendência ao prazer" ${ }^{\prime 0}$. Outra semelhança entre estes dois 
autores é a de que o prazer não é o fim para toda a ação humana, mas que "as ações do sujeito são determinadas pelo prazer que está presente no próprio ato de representação da ação a se realizar" 41 .

Uma diferença entre Hume e Freud, exposta por Monteiro, é a de que Hume nunca buscou explicar afecções originais de prazer e dor. Estas respostas, para Hume, não seriam dadas pela filosofia moral, mas, sim, pelo fisicalistas ou psicofisicalistas, justamente a quem Freud recorreu para fundamentar o princípio de prazer.

João Paulo Monteiro nos lembra que "junto ao princípio de prazer, a teoria psicanalítica propõe um princípio de realidade ${ }^{42}$. Ou seja, quando o sujeito não encontra o prazer junto à realidade ele estabelece uma fuga e, assim, a recusa da dor se dá mediante a alucinação. Todavia, a "realização autêntica do desejo exige do sujeito um exame de realidade e, assim, surge a capacidade de pensar, como substituta do desejo alucinatório" ${ }^{43}$, assim surgindo o princípio de realidade.

É justamente o mesmo conflito entre a tendência ao prazer e o mundo exterior que leva Hume ao exercício do entendimento. As paixões calmas são para Hume um exemplo de prazer determinado pelo entendimento e não pela imaginação, como no caso das paixões violentas, onde temos que "a razão é e deve ser escrava das paixões" ${ }^{44}$. Neste momento de razão escrava das paixões, João Paulo Monteiro equivale a teoria humeana à concepção freudiana da substituição do princípio de prazer pelo princípio de realidade ${ }^{45}$.

No que tange a uma concepção de uma gênese natural e inconsciente do entendimento, João Paulo Monteiro aproxima novamente Hume e Freud, pois "do mesmo modo que Hume rompe a autonomia do entendimento clássico (... ) Freud desprende a capacidade de enfrentar o mundo das camadas mais primárias do sujeito" ${ }^{46}$. É o que ocorre, segundo João Paulo Monteiro, com o conceito de justiça. Neste conceito, Hume propõe a substituição do princípio de prazer pela realidade, e "é para garantir o maior prazer possível que a justiça é instituída", para Hume. ${ }^{47}$ Também para Freud, Monteiro nos diz que "a sociedade é regida pela justiça"48 que distancia a sociedade da barbárie e a torna civilizada. Deste modo, "nas teorias de Hume e Freud, a justiça é ao 
mesmo tempo a consagração e a cristalização da sociabilidade e o instrumento que torna possível sua preservação" ${ }^{49}$.

O último capítulo de Hume e a Epistemologia investiga como se relacionam o senso comum e o conhecimento teórico. De acordo com João Paulo Monteiro, Hume sustenta uma insensível continuidade entre ambos, uma vez que a filosofia destrói as mais arraigadas crenças do senso comum e também as mais naturais. A consequência disto seria o ceticismo pirrônico, mas Hume propõe escapar a este destino com a teoria da natureza humana pois, para ele, o saber teórico seria apenas uma ampliação do senso comum. Por conseguinte, o saber teórico daria um salto em relação ao senso comum para além do inobservável, podendo inclusive, desqualificá-lo em relação ao senso comum.

Para João Paulo Monteiro, ao invés de uma ciência positiva, temos um senso comum conjectural e em continuidade com um saber teórico, caracterizado como um sistema de hipóteses em que a diferença entre as conjecturas derivadas do senso comum e a teórica está em que as do senso comum são inatas, instintivas e, portanto, naturais, e as teóricas são produto da reflexão e do trabalho da ciência. Ou seja, temos uma irremediável fratura entre essas duas conjecturas, e nenhuma perspectiva de encontrarmos continuidade nesses dois níveis do conhecimento humano.

Este texto termina e nos deixa a obrigação de voltarmos à obra de Hume, de lermos novamente o filósofo escocês, de chamarmos nossos alunos de volta e dizermos: vamos ler novamente os Diálogos, não falaremos mais em indução na filosofia de Hume, junto a tantas outras questões que não devem mais ser pensadas à luz da interpretação tradicional.

\section{Referências bibliográficas}

AYER, A. Language, Truth and Logic. Harmondsworth: Pelican, 1972.

HUME, D. An Enquiry Concerning Human Understanding (1748). Ed. Tom L. Beauchamp. Oxford: Oxford University Press, 1999.

. Dialogues Concerning Natural Religion (1779). Ed. Norman Kemp Smith. Oxford: Clarendon Press, 1935.

. A Treatise of Human Nature (1739-40). Eds. David Fate Norton e Mary J. Norton. Oxford: Oxford University Press, 2000.

. Essays Moral, Political and Literary (1752). Ed. Eugene F. Miller. Indianapolis: Liberty Fund, 1985. 
. The Natural History of Religion (1757). Ed. H. E. Root. London: Adam \& Charles Black, 1956.

MONTEIRO, J. P. G.. Novos Estudos Humeanos. $1^{\text {a }}$ Ed. Brasileira da obra publicada em 1984 pela Imprensa Nacional, Lisboa. São Paulo: Discurso Editorial, 2003. . Hume e a Epistemologia. São Paulo: UNESP, 2009.

NOXON, J. Hume's Philosophical Development. Oxford: Oxford Clarendon Press, 1973. PEARS, D. Hume's System. New York: Cambridge University Press, 1990.

PASSMORE, John. Hume's Intentions. Cambridge: Cambridge University Press, 1952. RUSSELL, Bertrand. The Problems of Philosophy. New York: Oxford University Press, 1997. 